\title{
Study on Effect of Soy sauce wastewater by SBR process Jinlong Zuo ${ }^{1}$, Xiaoyue Wang $^{1}$, Xinguo Yang ${ }^{1}$,Daxiang Chen ${ }^{1}$, Xuming Wang ${ }^{2 \star}$ \\ ${ }^{1}$ Life Science and Environmental Science Research Center, Harbin Commercial University, Harbin 150076,China
}

${ }^{2}$ Beijing Agro-Biotechnology Research Center, Beijing Key Laboratory of Agricultural Genetic Resources and Biotechnology, Beijing Academy of Agriculture and Forestry Sciences, Beijing 100097, China

* Corresponding author: Xuming Wang (wangxm413@163.com),Tel. +8613520716400

Keywords: soy sauce wastewater, SBR, COD

\begin{abstract}
In this study, soy sauce wastewater was treated with SBR process. The effects of culture time, $\mathrm{pH}$ and aeration time on the removal of COD were investigated. The SBR process is a biological treatment method with simple structure and nimble operation. In this paper in order to study the removal effect of soy sauce wastewater, the SBR process was divided into anoxic stirred for $0.5 \mathrm{~h}$, $\mathrm{pH}$ was controlled 5-9, and aerated for 1-3 hours. The initial COD, ammonia nitrogen, orthophosphate concentration of soy sauce wastewater is $1500-2000 \mathrm{mg} / \mathrm{L}, 75-99 \mathrm{mg} / \mathrm{L}, 9-12 \mathrm{mg} / \mathrm{L}$. The result shows that when solution $\mathrm{pH}$ was 7 , the aeration time was $3 \mathrm{~h}$, COD removal rate reached $86.2 \%$, ammonia nitrogen removal rate reached $83.67 \%$, and orthophosphate removal rate reached $88.9 \%$.
\end{abstract}

\section{Introduction}

Soy sauce is commonly used in China, soy sauce wastewater collected from soy sauce food industry. The vast majority of soy sauce wastewater is a kind of wastewater which is difficult to be treated, and once it is improper handled then it would be discharged into water environment, then it will cause irreparable harm to animals and plants health. Soy sauce wastewater contains a lot of organic matter, sugar, microorganisms and so on. It is a kind of refractory organic wastewater ${ }^{[1]}$.

Characteristics of soy sauce wastewater: Soy sauce wastewater has dark color, soy sauce fermentation process react polysaccharide reaction (maillard reaction) to form the black, and in the production of soy sauce is added caramel color ${ }^{[2]}$. Soy sauce wastewater has shock load changes, there are seasonal changes in the water quality of soy sauce wastewater, the fluctuation of wastewater quality is large. The contamination component of soy sauce wastewater is not stable, soy sauce factory product many kinds of productions, therefore, the composition of wastewater is very complex. Soy sauce wastewater with high concentration of organic matter, it has good biodegradability.

The activated sludge process is the most commonly used technology for biological wastewater treatment. SBR process is also called sequencing batch reactor activated sludge process. It consists of 5 steps: inletting water, stirring, aeration, sedimentation and drainage.

Characteristics of SBR: The process is simple and steady, resistance to shock loading, and low cost. It can inhibit sludge expansion and easy to achieve a high degree of automation.

\section{Materials and Methods}

\subsection{Equipment}

Electric oven thermostat (Shanghai YiHeng Technology Co. Ltd), Microwave digestion device (Shaoguan Taihong medical instrument), 752 UV visible spectrophotometer (Shanghai Chaojing science and Technology Co. Ltd.) 


\subsection{Preparing for domesticate sludge}

Sludge used in the experiment, from the return sludge secondary sedimentation tank of a wastewater treatment plant. The activity of the sludge was low, which showed dark brown, much impurities, large water content, and could not be used directly. To filter out the moisture in the sludge, and then carry out the sludge acclimation to make microbial grow ${ }^{[5]}$. After 30 days, sludge compact structure, and the taste of the soil, showing brown sludge and settling performance of sludge is good ${ }^{[6]}$.Preparation of the nutrient solution needs to meet the COD: $\mathrm{N}: \mathrm{P}=100: 5: 1^{[7]}$, COD is supplied from glucose $\left(\mathrm{C}_{6} \mathrm{H}_{12} \mathrm{O}_{6}\right), 1 \mathrm{~g}$ glucose can produce $1.067 \mathrm{gCOD}, \mathrm{N}$ is provided by ammonium $\mathrm{NH}_{4} \mathrm{Cl}$, $\mathrm{P}$ provided by $\mathrm{KH}_{2} \mathrm{PO}_{4}$. All chemicals were analytical grade without further purification.

\subsection{Preparing for simulated soy sauce wastewater}

Soy sauce wastewater was diluted by "Zheng yang river" sauce, diluted into the concentration of COD, ammonia nitrogen, orthophosphate is about 1500-2000mg/L, 75-99mg/L, 9-12mg/L.

\subsection{Process Startup and Operation}

SBR reactor is a cylindrical organic glass container, the volume of 10 liters, the stirring paddle depth bottom of the reactor, the aerator also reach the bottom of the reactor, the air pump provides oxygen. The bottom is a cone design, the bottom part of the reactor is provided with a sludge discharge pipe. In the wall of the reactor main body in the vertical direction, it has four sampling port. In this study, employ semi-limit aeration. SBR was anoxic stirred 0.5h (hypoxia), aerated $3 \mathrm{~h}$ (aerobic) and precipitated for 2 hours. The rest of the time is idled, and the aeration of the idle period is used for sludge regeneration.

\section{Results and discussion}

\subsection{Effect of culture time on COD removal efficiency}

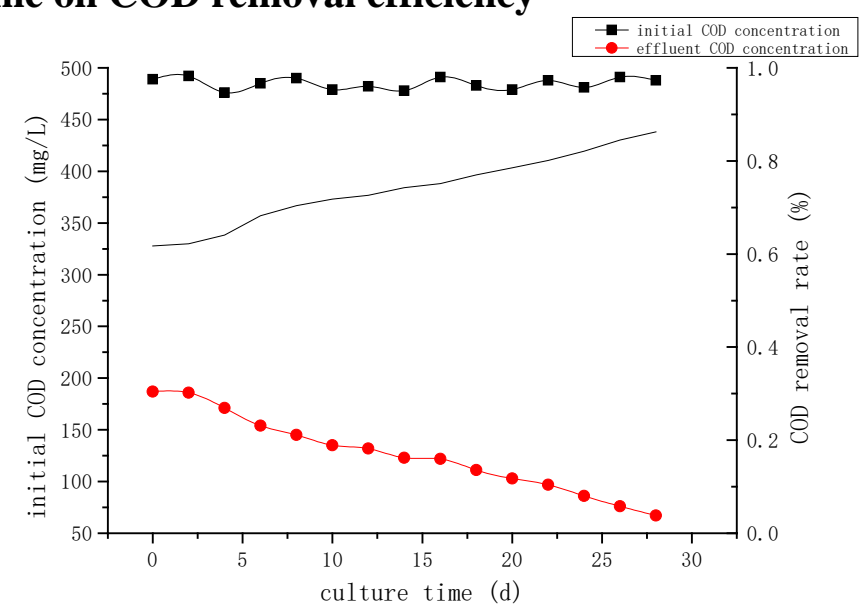

Fig.1.effect of culture time value on COD removal efficiency

Fig.1. shows that when the initial COD concentration is about $500 \mathrm{mg} / \mathrm{L}$, with the increase of culture time, the effluent COD concentration is decrease, the removal rate of COD increased, When cultivate for 30 days, COD removal rate reached $88 \%$. Microorganism in sludge convert organic substances into carbon dioxide and water and other inorganic substances ${ }^{[8]}$.

\subsection{Effect of $\mathrm{pH}$ value on COD removal efficiency}

Adjust $\mathrm{pH}$, the reactor is operated under different $\mathrm{pH}$ conditions, SBR was stirred 30min, and then aerated 3 h, precipitated $2 \mathrm{~h}$. 


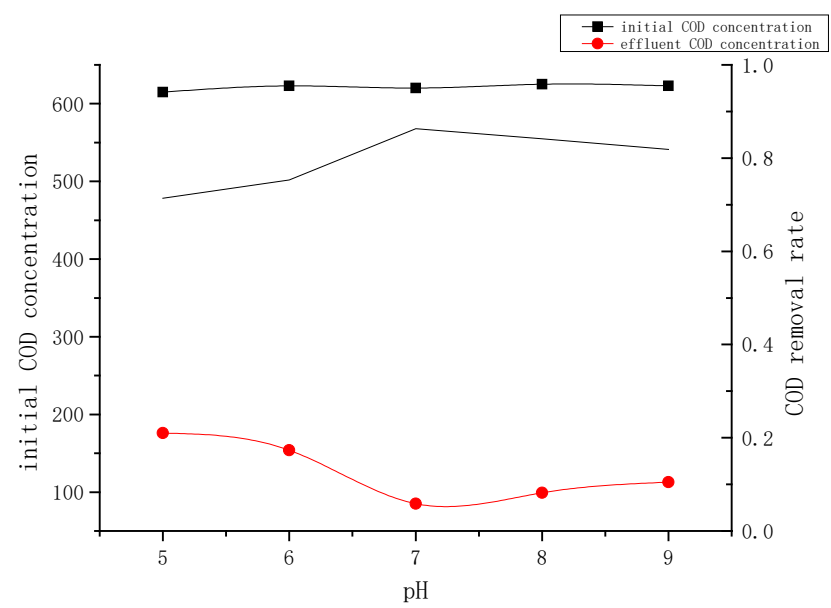

Fig.2.effect of $\mathrm{pH}$ value on COD removal efficiency

Fig.2. shows that the effect of $\mathrm{pH}$ value on COD microbial degradation activity and effect of $\mathrm{pH}$ value is obvious. With the increase of $\mathrm{pH}$ value, curve shows a trend of rise till 7, then curve shows a trend of decline. When the solution $\mathrm{pH}$ value is 7 , the removal efficiency is $86.2 \%$. Therefore, $\mathrm{pH}$ value is selected as 7 . Microorganisms are suitable for survival under neutral conditions.

\subsection{Effect of reacting time value on COD removal efficiency}

Soy sauce wastewater was added in the reactor. After the anoxic stirred for 30 minutes and aerated $1 \mathrm{~h}, 1.5 \mathrm{~h}, 2 \mathrm{~h}, 2.5 \mathrm{~h}, 3 \mathrm{~h}$.

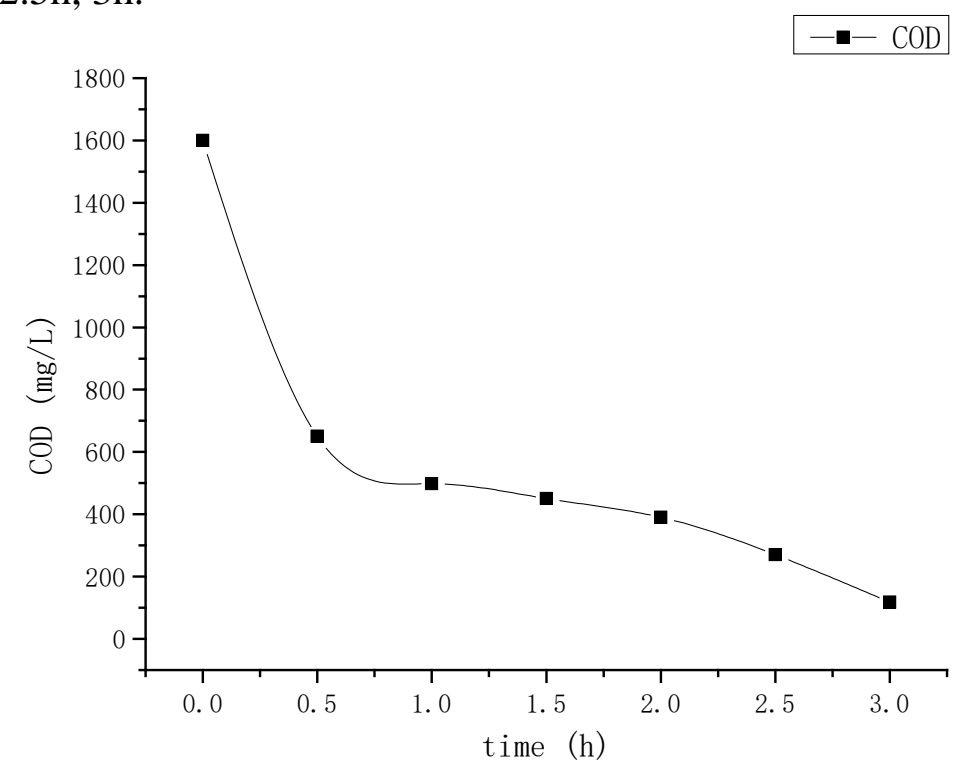

Fig.3.effect of reacting time value on COD removal efficiency

Fig.3. shows that the effect of reacting time value on COD microbial degradation activity and effect of $\mathrm{pH}$ value is obvious. With the increase of time value, curve shows a trend of reducing the rise. When the solution reacting time value is $3 \mathrm{~h}$, the removal efficiency is $87 \%$. Therefore, reacting time value is selected as $3 \mathrm{~h}$. 


\subsection{Effect of SBR on the treatment of ammonia nitrogen and orthophosphate}

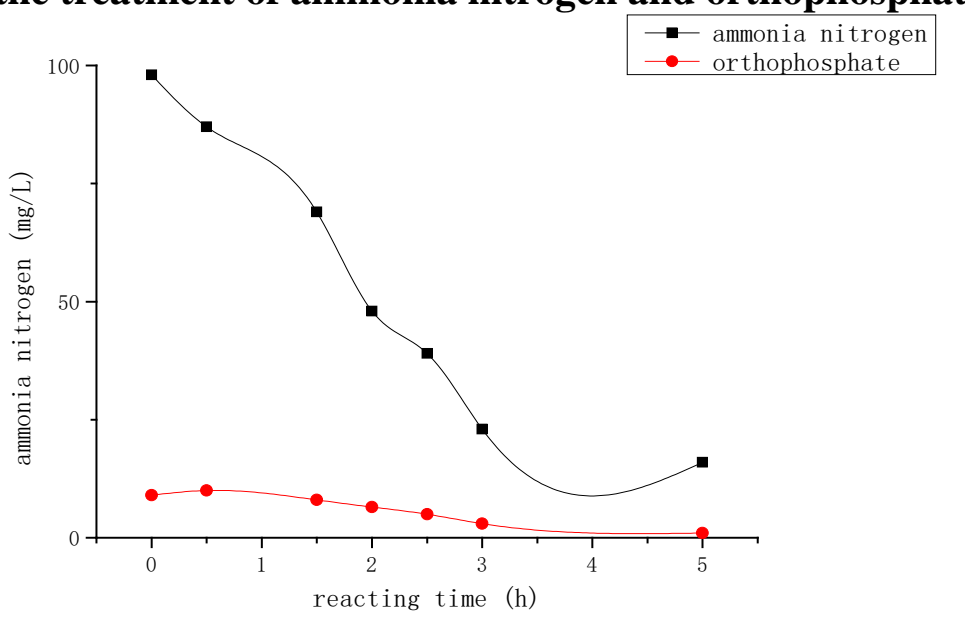

Fig.4. effect of SBR on the treatment of ammonia nitrogen and orthophosphate

Fig.4. shows that ammonia nitrogen decreased gradually, the ammonia nitrogen was converted to nitrite and nitrate by nitrification and denitrification, and the nitrate nitrogen was converted into nitrogen by denitrification, the removal rate is $83.67 \%$. Orthophosphate first increased and then decreased, the removal rate is $88.9 \%$. Biological phosphorus removal phosphorus was dissolved, absorbed by microorganisms and thus discharged as excess sludge ${ }^{[10]}$. Under the anaerobic condition, phosphorus release, under aerobic conditions, the phosphate accumulating bacteria absorb phosphorus.

\section{Conclusions}

It is concluded that: When soy sauce wastewater initial COD is $1500-2000$, when pH value is 7 , aeration time is $3 \mathrm{~h}, \mathrm{COD}$, ammonia nitrogen, orthophosphate removal rate reached $86.2 \%$, 83.67\%, $88.9 \%$ respectively.

\section{References}

[1] Hasnida Harun, Aznah Nor-Anuar. Development and Utilization of Aerobic Granules for Soy Sauce Wastewater Treatment: Optimization by Response Surface Methodology. Journal Technology, 2014, 69(5):32-33.

[2] Sapers, G. M. Browning of foods: control by sulfites, antioxidants, and other means [J].Food Technology, 1993, 10: 75-8.

[3] H. Chmiel, M. Kaschek. Concepts for the treatment of spent process water in the food and beverage industries. Desalination, 2002, 43(8):110-112.

[4] Hanqing Yu, et al. Post treatment of Effluent from Coke-plant Wastewater Treatment System in Sequencing Batch Reactor [J]. J of Environ Engineering. 1997, (3): 305-308.

[5] EBIE K .Activation Mechanism and Effectiveness in Reusing Sludge from Water Purification [J]. Water Science and Technology. 2000, 42(3-4): 273-281.

[6] Carrera, J. Vicent, T. Lafuente, J. Effect of influent COD/N ratio on biological nitrogen removal (BNR) from high-strength ammonium industrial wastewater[J].Process Biochemistry,2004,(39);2035-2041

[7] Q. Fontenot, C. Bonvillain, M. Kilgen and R. Boopathy. Effects of Temperature, Salinity and Carbon: Nitrogen Ratio on Sequencing Batch Reactor Treating Shrimp Aquaculture Wastewater [J]. Bio resource Technology, 2007, 98(9):1700-1702

[8] Inanc B, Ciner F, Ozturk I. Color removal from fermentation industry effluents [J]. Water Science and Technology, 1999, 40(1):331- 338 
[9] Bae W, Chung JW.A Shortcut biological nitrogen removal in a biofilm reactor by suppressing nitrite oxidation. Bio gradation (in preparation), 2002.

[10] Fikret Kargi, Ahmet Uygur. Nutrient Removal Performance of a Sequencing Batch Reactor as a Function of the Sludge Age [J]. Enzyme and Microbial Technology. 2002, 31(6): 842-847. 